\title{
ERRATUM TO: QUANTIFYING ADVENTITIOUS ERROR IN A COVARIANCE STRUCTURE AS A RANDOM EFFECT
}

\author{
HAO WU
}

BOSTON COLLEGE

MichAEL W. BROWNE

THE OHIO STATE UNIVERSITY

\section{Erratum to: PSYCHOMETRIKA-VOL. 80, NO. 3, 571-600 SEPTEMBER 2015 DOI: 10.1007/s11336-015-9451-3}

The MATLAB program files and the description file mentioned in Sect. 11 of the original paper were included in the review process but were missing when the paper was published online. They are now included as the electronic supplementary materials to this erratum.

Springer regrets the error.

Published Online Date: 21 NOV 2016

Electronic supplementary material The online version of this article (doi:10.1007/s11336-016-9542-9) contains supplementary material, which is available to authorized users.

The online version of the original article can be found under doi:10.1007/s11336-015-9451-3

Correspondence should be made to Hao Wu, Department of Psychology, Boston College, Chestnut Hill, MA 02467, USA. Email: hao.wu.5@bc.edu 